\title{
Satisfeitos na pobreza? Sobre o argumento da divisão social em Maquiavel
}

\section{Satisfied in poverty? On Machiavelli's argument of social division}

\author{
Lucas Cardoso Petroni ${ }^{1}$
}

\begin{abstract}
Resumo
Este trabalho tem por objetivo reconstruir a famosa tese da divisão social entre grandes e povo, tal como encontrado nas principais obras de Maquiavel, no intuito de evidenciar as consequências normativas do argumento para a teoria política contemporânea. Em especial, procurar-se-á dar ênfase à posição normativa do povo no argumento maquiaveliano como uma posição necessária em contextos de autoridade política centralizada. Por fim, o artigo procura esboçar, em linhas gerais, duas apropriações possíveis da tese da divisão social. O conceito de "povo" exerce, em cada uma delas, consequências normativas distintas, respectivamente, como uma ferramenta importante contra formas de opressão social, e como a única fonte possível de legitimidade do poder político.
\end{abstract}

Palavras-chaves: Maquiavel. Teoria política. Divisão Social. Autoridade política.

\begin{abstract}
The article aims to reconstruct the famous thesis about the social division between the powerful ones and the people, as it is presented in Machiavelli's major works, in order to follow some important normative implications for contemporary political theory. Particularly, it brings about the conceptual position of "people" in Maquiavelli's argument understood as a necessarily positional function under centralized political authorities. Finally, the article tries to present, in very broad strokes, two alternative appropriations of the argument. The notion of "people" plays two distinctive roles in each of these traditions, respectively, as an important tool against social oppression, and as the only possible source for political legitimacy.
\end{abstract}

Keywords: Machiavelli. Political Theory. Social Division. Political Authority.

\footnotetext{
Doutorando no Departamento de Ciência Política da USP. Pesquisador associado ao Political Theory Group da Universidade do Minho (Portugal) e pesquisador visitante no Departamento de Filosofia da Universidade de Yale. Agradeço a Bruno Santos, João Cortese, Raissa Ventura, Roberta Soromenho, Sérgio Cardoso e um parecerista anônimo pelas críticas e comentários feitos a esse artigo. As eventuais imprecisões e irresponsabilidades argumentativas são de minha responsabilidade. Agradeço também o suporte institucional fornecido pela FAPESP, pelo PROEX/CAPES e pelo Departamento de Ciência Política da USP.
} 


\section{Introdução}

O papel de Maquiavel como crítico da moralidade política de seu tempo encontra-se sedimentado na tradição de seus comentadores. Por um lado, Maquiavel argumentou de modo direto pela importância da força na ação política, revelando os modos pelos quais essa lógica pode entrar em conflito com moralidades distintas tal como a moralidade cristã de seu tempo ${ }^{2}$. Por outro, o florentino não poupou seus companheiros republicanos que, ao recorrerem às noções clássicas de virtude individual e bem comum como valores políticos fundamentais, denegaram com isso, nas palavras de Claude Lefort, "o fato irredutível da divisão social” (LEFORT, 1979a, p. 255)³.

De fato, dos muitos legados de sua obra para a teoria política contemporânea, a tese da divisão social entre "grandes" (grandi) e "povo" (popolo) talvez seja a mais importante. Segundo essa tese, toda forma de organização política, por mais particular que possa aparecer à primeira vista, é estruturada a partir de um mesmo confronto posicional entre duas forças contraditórias: aqueles que querem oprimir, os grandes, e aqueles que não querem ser dominados, $\mathrm{o}$ povo. Para o pensamento maquiaveliano, qualquer agente político que subestime a importância dessa divisão estaria fadado ao desastre político.

Um exemplo típico desse engano poderia ser encontrado, por exemplo, na crença segundo a qual existiria uma conciliação pacífica possível entre essas duas forças políticas fundamentais. Podemos, é claro, utilizar essa crença estrategicamente, mas não faria sentido defendê-la normativamente.
Isso porque, como nos diz Maquiavel, os grandes e o povo possuiriam "desejos antagônicos", impossíveis, portanto, de serem saciados pelos mesmos fins ${ }^{4}$. Se os recursos políticos e materiais disponíveis em nosso mundo social são sempre escassos, então é impossível satisfazer ambos os desejos. $\mathrm{Na}$ verdade, a própria natureza aquisitiva dos desejos seriam capazes de escassear até mesmo recursos materialmente abundante ${ }^{5}$. Como afirma Maquiavel em seus Comentários Sobre a Primeira Década de Tito Livio [a partir de agora TL], “[A] natureza criou os homens com a sede de tudo abraçar e a impotência de atingir todas as coisas", isto é, a escassez de recursos sociais é fruto, sobretudo, das disposições aquisitivas dos homens e não apenas da natureza desses próprios recursos ${ }^{6}$. Quando um lado ganha o outro, necessariamente, perde. Apelar ao "bem comum" da comunidade política fundado em uma solução perfeitamente harmônica não passaria de uma ilusão. E, segundo a sabedoria política de Maquiavel, auto-ilusões são sempre perigosas em matéria de política.

As consequências extraídas por Maquiavel da tese da divisão tendem a ser, em geral, favoráveis às aspirações populares - o povo contra os grandes. Tanto em $O$ Príncipe [a partir de agora OP] como nos TL, temos um sem número de exemplos de como o povo é mais confiável e mais estável em seus interesses do que os grandes. Fato esse que, especialmente no contexto das repúblicas, faria do povo um melhor "guardião da liberdade" do que a eventual "excelência" dos grandes ${ }^{7}$. Roma seria um bom exemplo dessa lógica. Segundo Maquiavel, a grandeza de Roma dependeria da boa expressão

2 A melhor exposição desse conflito de valores ainda é encontrada em Berlin (1977). A esse respeito, ver também retomada da tese de Berlin em Skinner (2009, p. 155).

3 Ver, por exemplo, Winter (2011 p. 72): “A originalidade do autor florentino reside no fato de conceber o conflito como elemento necessário à esfera política".

${ }^{4}$ OP IX p. 77. As referências às obras de Maquiavel seguirão a seguinte nomenclatura: Comentários Sobre a Primeira Década de Tito Lívio [TL], O Príncipe [OP] e História de Florença [HF]. No caso dos Comentários e da História o numeral romano indica o livro e o numeral arábico o capítulo no qual a passagem mencionada se encontra. No caso de O Príncipe o numeral romano se refere ao capítulo da obra. As edições traduzidas utilizadas podem ser consultadas na bibliografia.

5 TL I 37.

${ }^{6}$ TL II Introdução.

7 CF. OP IX e TL I 16. Maquiavel menciona o povo como "guardião da liberdade" em TL I 5. 
dos interesses populares nas leis e instituições republicanas. A institucionalização da liberdade popular nas principais instituições romanas teria permitido frear os interesses destrutivos dos nobres romanos, levando Roma a ser uma experiência política ao mesmo tempo livre e grandiosa. Isso significa que a tese da divisão possui duas dimensões: primeiro, ela reconhece um fato a respeito da organização política humana - a divisão civil entre grandes e povo - e, segundo, utiliza esse conhecimento tanto para desfazer as falsas pretensões normativas dos discursos da unidade social, quanto para nos auxiliar na engrenagem institucional de um bom regime.

Sendo assim, do ponto de vista da teoria política contemporânea, a tese da divisão social coloca o seguinte problema: se a divisão é de natureza objetiva, se o conflito de interesses entre grandes e povo é necessário do ponto de vista da organização do poder entre homens e mulheres, deveríamos nos perguntar se essa divisão não valeria também para o outro lado. Ou seja, se é verdade, por um lado, que em um bom regime encontramos os anseios do povo assegurados por boas leis (ou pela atenção cuidadosa do príncipe), também deveria ser verdade, por outro, que a própria distinção entre grandes e povo não pode ser suprimida. Uma vez que a divisão social engendra uma relação de desigualdade frente ao poder, sempre existirão alguns poucos detentores do poder político, de um lado, e o povo, destituído desse mesmo poder, do outro. A necessidade da divisão se tornaria uma forma de justificação da desigualdade social. Se para o discurso político da época de Maquiavel a tese certamente serviu para refutar discursos aristocratas de fundo naturalista, o que Maquiavel teria a dizer acerca de moralidades políticas fundadas na igualdade material de todos os cidadãos? Subitamente, a famosa crítica à ideologia renascentista de Maquiavel torna-se a justificação contemporânea da desigualdade: caberia ao povo satisfazer-se na pobreza para a eficiência institucional do regime ou para a grandeza da pátria.

Construído dessa forma apressada, o argumento é um tanto caricatural e certamente não respeita as famosas dificuldades de interpretação que a obra de Maquiavel traz. Entretanto, se por um lado essa reconstrução é ruim do ponto de vista da riqueza do texto e do trabalho sério da exegese, por outro ele nos permite explorar de maneira mais precisa alguns dos pressupostos da tese maquiaveliana da divisão social, tese essa que, recentemente, tem sido amplamente recuperada pela teoria neorepublicana ${ }^{8}$.

O objetivo neste trabalho é justamente analisar algumas das consequências normativas da tese da divisão social e de que modo podemos pensála na teoria política contemporânea. Para isso, será preciso, em primeiro lugar, reconstruir a tese da divisão social dando especial atenção a alguns componentes conceituais importantes, como a forma e a natureza normativa dos dois tipos fundamentais de reivindicação política. O objetivo não será, como afirmei, fornecer uma interpretação estrutural de Maquiavel ("aquilo que está lá no texto") nem tampouco propor uma nova interpretação ou mesmo uma crítica velada às demais interpretações vigentes ("aquilo que Maquiavel deveria ter concluído em seu texto"). O artigo procura apenas reapresentar o argumento de um modo que seja particularmente apropriada à discussão contemporânea. A pergunta principal a ser colocada será: deve o povo se satisfazer na pobreza?

Em seguida, duas formas distintas de apropriação da tese da divisão são formuladas e contrastadas. A despeito das classificações usuais, gostaria de propor uma nova forma de classificação das teorias de inspiração maquiaveliana tomando por critério,

\footnotetext{
8 Alguns exemplos de teóricos neorepublicanos que interpretaram a tese da divisão de Maquiavel serão apresentados ao longo do artigo. A respeito das origens do neorepublicanismo, seus argumentos e seu papel entre as principais teorias políticas contemporâneas, ver Skinner (1997), Pettit (1997) e Bignotto (2013). O argumento apresentado neste trabalho não pretende fazer uma avaliação sistemática das teorias neorepublicanas, mas apenas utilizar alguns de seus principais expoentes (ex., Skinner e Mccormick), como ilustração de uma maneira específica de interpretar a tese da divisão.
} 
respectivamente, dois argumentos normativos extraídos dos escritos de Maquiavel, a saber, duas maneiras distintas de entender o papel do povo na divisão do poder. Cada uma delas oferece uma visão diferente do papel da soberania popular: na primeira, a tese é fundada no equilíbrio entre forças sociais antagônicas e o povo é entendido como uma forma de contrapoder às oligarquias, na segunda, a tese é reinterpretada a partir do ideal democrático de soberania popular e o povo é entendido como a única fundamentação legítima para o poder político.

\section{I}

Deve o povo se satisfazer na pobreza? Aprimeira reação a essa pergunta pode ser de natureza cética. Afinal, seria estranhamente anacrônico demandarmos de Maquiavel a possibilidade de sociedades nas quais todos fossem, de jure, iguais em poder. Contudo, ainda que tenhamos que esperar mais dois ou três séculos para formular com precisão os ideais contemporâneos de igualdade política, não é impossível afirmarmos que Maquiavel fosse completamente indiferente a aspirações igualitárias. Encontramos essa inspiração, por exemplo, nas palavras de um líder operário revolucionário de Floresça segundo as quais todos os homens "são idênticos" entre si e, portanto, não há nada de necessário no que diz respeito à propriedade e ao poder ${ }^{9}$. O discurso revolucionário de Florença representa uma defesa direta da distribuição igualitária (ou pelo meno mais igualitária) do poder. Contudo, para Maquiavel, ainda que seja possível argumentar sobre a defesa de uma posição igualitária diante do poder, não podemos, segundo a tese da divisão, conceber o fim da diferença entre grandes e povo, isto é, o fim da divisão social. Não seria, então, o caso de concluirmos que no discurso igualitário dos campeões do povo, de modo análogo ao discurso da unidade aristocrática, também estaríamos diante de uma ilusão? A ilusão de que não existe, afinal, vida social sem a divisão entre dominantes e dominados.

Encontramos uma indicação da preocupação de Maquiavel com esse problema nos capítulos dos Comentários nos quais ele procura explicar o fim da república romana pela tentativa de reforma agrária liderada pelos irmãos Graco. Segundo Maquiavel, mesmo após a instituição do Tribunato, que havia garantido a liberdade popular, o povo de Roma não parou de almejar dos nobres "sua riqueza e suas honrarias", o que teria levado a plebe a endossar com fervor as propostas de redistribuição das terras produtivas. Ora, conclui sumariamente o autor, "como num governo bem organizado o Estado deve ser rico, e os cidadãos pobres, é de se supor que esta lei fosse defeituosa" ${ }^{\prime 10}$. Isto é, a lei agrária rompeu o delicado equilíbrio de poderes sociais vigentes na república romana: insatisfeitos com a liberdade política, a plebe almejou também a igualdade material.

Mais adiante no terceiro livro, Maquiavel nos fornece outro exemplo desse raciocínio. Ao discorrer sobre a pobreza exemplar de Cincinato, o autor enaltece sua virtude por meio de suas posses: Cincinato possuiria "não mais que quatro jeiras de terra". Por meio dessa história encontramos uma ilustração exemplar do período no qual a república romana ainda não tinha sido corrompida pela riqueza e, principalmente, pela ambição por recursos materiais. "Satisfeitos na pobreza", conclui Maquiavel, "os cidadãos se contentavam [naquele tempo] com a glória que a guerra lhes podia dar" ${ }^{11}$.

Mesmo se adotarmos uma interpretação estrutural dessas passagens e creditarmos o desejo econômico do povo à imitação dos hábitos dos nobres, não deixa de ser verdade que, para Maquiavel, uma das principais causas da queda da república foi justamente o desejo desmedido do povo romano em deixar de ser apenas povo

9 HF III 1. Ver também LEFORT, 1979b, p. 152.

10 TL I 37.

11 TL III 25. 
(ADVERSE, 2007 p. 39). Ao quererem aquilo que não poderiam obter, isto é, a propriedade dos grandes, o povo rompeu o bom equilíbrio entre a ambição contida dos nobres por dominação e o desejo igualmente contido do povo em equalizar as distinções sociais de Roma. O raciocínio não nos deveria causar espanto. Afinal, como vimos, a natureza da divisão social é da ordem da necessidade: não existe realidade social sem dominantes e dominados. Tentar aboli-la é ilusório e, como nos mostra a experiência de Roma, potencialmente perigoso para a liberdade. De um ponto de vista realista - característico de Maquiavel - o melhor que podemos almejar seria encontrar um meio de equilibrar essa divisão, explorando-a para o benefício coletivo.

Caberia ao povo, desse modo, satisfazer-se na pobreza para a eficiência e grandeza institucional do regime? Para responder essa pergunta devemos, em primeiro lugar, entender qual a natureza dessa devisão e de que forma ela pode explicar as relações de poder em uma comunidade política.

São muitas as passagens que tratam da divisão entre grandes e povo nos escritos de Maquiavel. Nem sempre a nomenclatura é constante. Por vezes encontramos outras distinções possíveis tais como "nobres", "aristocratas" e, no caso romano, o "senado" como classe superior e antagônica ao povo. No entanto, tomaremos a distinção entre grandes e povo como ilustração básica da divisão social já que o modo como cada sociedade determina historicamente suas classes (Roma, Europa Medieval, Veneza, etc.) é secundária em relação a existência do fato da divisão. Além disso, podemos argumentar que a própria ausência de uma distinção nítida entre as diferentes nomenclaturas do polo social dominador - aristocratas e oligarcas, por exemplo - já constitui por si mesmo um argumento forte contra a tradição aristocrática que procura justificar a divisão social a partir ds virtudes das classes dominantes ${ }^{12}$.

Como ponto de partida, existem duas caracterizações canônicas da tese da divisão que merecem ser mencionadas. No nono capítulo de $O P$, ao aconselhar àqueles que não contam nem com a ajuda de exércitos estrangeiros nem com o poder hereditário para obter o controle do Estado - ou seja que só contam com a própria astúcia e perseverança (LEFORT, 1972, p. 352-352) - Maquiavel afirma que existem apenas duas possibilidades de se alcançar o poder. Ou bem um príncipe novo ascende ao poder "com o apoio popular" ou com "o [apoio] dos poderosos"13. Isso porque, para Maquiavel,

[...] em toda cidade se encontram essas tendências opostas: de uma parte, o povo não quer ser comandado nem oprimido pelos poderosos, de outra, os poderosos querem comandar e oprimir o povo; desses dois desejos antagônicos advém nas cidades uma das três consequências: principado, liberdade ou desordem ${ }^{14}$.

Por que um príncipe poderia contar apenas com esses dois caminhos para chegar ao poder? Segundo a explicação maquiaveliana, porque apenas tais classes seriam fortes e coesas o bastante para alterar definitivamente a estrutura de poder de uma comunidade política. Digamos, por exemplo, que os grandes se sintam enfraquecidos diante do poder popular. A melhor saída para eles, de acordo com seus interesses, seria justamente tornar príncipe um dos seus pares, "a fim de saciar seus próprios interesses a sua sombra"15. Ao contrário, caso o povo perceba que os poderosos estariam prestes a extinguir liberdades adquiridas, ou simplesmente a oprimir ainda mais o povo, rapidamente eles elegeriam um dos poderosos para que possam "ser protegidos por sua autoridade"16.

\footnotetext{
12 Tanto Mccormick (2001, p. 302), como Lefort (1972), chamam atenção para a polêmica ausência de distinção entre diferentes classes de dominantes.

13 OP IX: 1.

14 Ibid.

15 Ibid.

16 Ibid.
} 
Se aceitarmos esse raciocínio podemos então fazer uma afirmação objetiva a respeito da natureza dos principados: para cada principado encontrado, ou ele se instituiu "com o povo" ou "contra o povo" e, a partir desse conhecimento, pode-se extrair as providências necessárias para a manutenção do poder. Disso se segue que a terceira opção fornecida por Maquiavel, a "desordem", não passa de uma possibilidade conceitual, já que, empiricamente, o conflito aberto entre as classes invariavelmente terminará com uma das duas triunfando sobre a outra: César em Roma, os Médicis em Floresça.

A divisão se encontra também, evidentemente, no interior das repúblicas. Em $T L$ encontramos a tese da divisão no momento em que o autor questiona a quem devemos confiar a proteção das instituições republicanas. "Como em todos os Estados existem aristocratas e plebeus", afirma Maquiavel, "podese bem perguntar em que mãos a liberdade estaria melhor salvaguardada" ${ }^{17}$. Nessa descrição da tese também temos duas tendências ou humores (umori) distintos: "se considerarmos o objetivo da aristocracia e do povo, perceberemos na primeira a sede do domínio; no segundo, o desejo de não se oprimido" 18 . Se no capítulo IX do príncipe o povo representava um perigo relativamente menor do que a ambição dos grandes, na segunda passagem o viés popular é explícito. Cabe ao povo proteger as instituições republicanas freando as pretensões privadas dos grandes. Por que caberia ao humor popular essa função?

A despeito da divisão entre duas classes opostas, é importante notarmos que Maquiavel não concebe os humores sociais como forças perfeitamente simétricas. Mas antes de entendermos essa assimetria precisamos responder a uma pergunta preliminar: o que é um "humor"? Não é fácil encontrarmos uma resposta precisa. Uma caracterização preliminar seria aquela segundo a qual um humor seria um compósito entre interesses e emoções que identificam a ação social de classes determinadas. Isto é, uma mistura entre cálculo de interesse racional e disposição afetiva invariavelmente encontrada nas comunidades políticas ao longo da história. A ideia de que se trata de uma combinação entre cálculo e paixão parece ser relevante. Caso os humores fossem apenas um cálculo racional eles não seriam socialmente determinados já que qualquer agente naquela posição teria exatamente os mesmos parâmetros para o cálculo. Caso fossem pura disposição afetiva, seria difícil reconhecermos padrões explicativos ao longo da história.

Quanto ao conteúdo dos humores, no entanto, Maquiavel é mais claro. Podemos separá-los em dois enunciados distintos:

(G): Os grandes querem comandar $e$ oprimir o povo;

(P): O povo não quer ser comandado nem oprimido por ninguém.

Em primeiro lugar, os humores são definidos como duas vontades ou reivindicações (um "querer que") contraditórias, mas não necessariamente contrárias. Por ser um enunciado universal, por não querer ser dominado por ninguém, o desejo popular (P) refuta ou bloqueia as pretensões particulares dos grandes. Por outro lado, $(\mathrm{G})$ é particular na medida em que os grandes querem dominar um grupo determinado, o povo. Entretanto, é fácil perceber que não existe complementariedade entre as duas formas de reivindicações já que suas respectivas estruturas enunciativas são distintas do ponto de vista formal. É nesse sentido, portanto, que $(\mathrm{G})$ e (P) são proposições contraditórias, mas não contrárias entre si.

Além disso, Maquiavel utiliza duas expressões distintas para caracterizar dominação: "opressão" em (G) e "comando" em (P). Não querer ser oprimido não é o sinônimo exato de não querer ser comandado. Digamos que alguém me oprima ao me obrigar a agir contra os meus interesses. A base de reivindicação da

17 TL I 5.

18 Ibid. 
minha queixa não necessita assumir que não quero ser comandado, ou que o problema com essa relação se encontra no fato de que alguém esta ordenando que realize uma ação, mas apenas que não gostaria de ser prejudicado em meus interesses diante de alguém mais poderoso do que eu. Em um contexto mais amplo, é perfeitamente possível conceber formas não-opressivas de comando como, por exemplo, obedecer a uma lei legítima. Se isso for verdade, então faz sentido falarmos que alguém está sendo oprimido ao ser comandado - visto que as duas relações não significam a mesma coisa. Objetar a uma relação de comando é, nesse sentido, mais forte do que objetar relações de opressão: mesmo relações assimétricas benéficas para aqueles que são sujeitados a elas poderiam ser rejeitadas por estabelecerem relações de comando entre comandantes e comandados - o paternalismo seria um bom exemplo.

Precisamos ter em mente a diferença entre os dois sentidos de dominação caso queiramos entender a natureza normativa da reivindicação popular. Por enquanto, basta reconhecer que, sendo as reivindicações formalmente assimétricas, elas possuem consequências políticas distintas em uma república. Voltemos ao argumento de Maquiavel: caso se queira manter a liberdade civil, uma liberdade incondicional contra todas as formas de ameaça, o melhor seria confiá-la à vontade universal do povo - "uma vontade mais firme de viver em liberdade" - ao invés de confiá-la à vontade particular dos grandes. Esse é o motivo pelo qual podemos concluir com Maquiavel que as aspirações populares são próprias à causa republicana, fazendo do povo "o guardião da liberdade"19.

Vemos portanto tese da divisão é, ao mesmo tempo, objetiva quanto a sua forma e determinada quanto ao conteúdo. Não apenas o conflito é a natureza concreta da política, na medida em que ele é recorrente em qualquer experiência social humana, como ele encontra uma forma determinada na divisão social entre dois humores, respectivamente $(\mathrm{G})$ e $(\mathrm{P})$. Cabe aos agentes políticos, e em especial aos príncipes e criadores de instituições republicanas, reconhecer esse fato. Contudo, se por um lado as duas passagens contam com um viés "popular" inequívoco, na medida em que o povo representa, ao mesmo tempo, um perigo menor aos príncipes novos e o verdadeiro fundamento das instituições republicanas, por outro, nada nos permite concluir que a eliminação do poder dos grandes seja possível. Ao contrário. No momento em que a distribuição de recursos sociais, como fama, dinheiro e, principalmente, autoridade política, é coletivamente reivindicada, a vontade popular encontra seu limite natural na boa ambição individualizada dos grandes.

Como vimos anteriormente no caso da Lei Agrária de Roma, é melhor confiarmos nas ambições divididas (e algo mesquinhas) dos nobres do que na vontade popular de equalizar os recursos materiais e, com isso, o poder. O exemplo da revolta Ciompi ilustra perfeitamente essa implicação da tese da divisão. Em A História de Florença [HF], Maquiavel relata as consequências políticas nefastas causadas pela tentativa de equalização do poder dos "ciompi", ou trabalhadores sem guildas, contra a aristocracia de Florença. Se na Roma republicana o povo "desejava gozar as supremas honras ao lado dos nobres", isto é, sem deixar de ser povo, já em Florença, afirma Maquiavel, o povo "combatia para ficar sozinho no governo, sem a participação dos nobres" 20 . Ao querer comandar, e não apenas não ser oprimido, a vontade do povo florentino era insuportável frente à vontade dos grandes, permitindo que as aspirações populares fossem suprimidas com mais furor do que em Roma. Novamente a tese da divisão nos obriga a respeitar a objetividade dos conflitos entre as duas classes: a luta pelo comando popular é tão precária quanto a tentativa aristocrática de sustentar privadamente as leis republicanas. Como nota Claude Lefort, do fato da divisão social segue-se que "toda sociedade se encontra dividida entre

\footnotetext{
19 Ibid.

20 HF III 1 (ênfase acrescida).
} 
dominantes e dominados" e não que um dos polos do conflito conte com uma legitimidade natural (LEFORT, 1972, p. 496). As reivindicações possuem forma e natureza distintas, mas de acordo com a tese apresentada por Maquiavel o poder político depende da coexistência (harmônica ou não) de ambas.

Mas qual é exatamente a natureza dessa necessidade? O que significa afirmar que a relação desigual entre dominantes e dominados, entre grandes e povo, entre detentores e sujeitos ao poder, é socialmente necessária?

Antes de prosseguirmos, gostaria de contestar uma maneira usual de responder a essa pergunta. A despeito de ser plausível e amplamente aceita, acredito que essa interpretação seja equivocada e que, com isso, acaba por distorcer o argumento maquiaveliano em um ponto crucial. De acordo com essa interpretação, a divisão social constituiria um "axioma" da análise política de Maquiavel, ou, equivalentemente, que tratar-se-ia de um postulado "ontológico" da sua concepção de sociedade (SKINNER, 1981, p. 105). Acredito que essa afirmação seja equivocada em pelo menos dois sentidos diferentes. Em primeiro lugar, porque ao postularmos uma tese tendemos a perder qualquer possibilidadedeesclarecê-la.Claro,épossívelassumir a tese sem nos perguntarmos sobre sua validade. Isso pode nos ajudar, por exemplo, a compreender os argumentos de Maquiavel. Mas o objetivo aqui é pensarmos sua validade - especialmente levando em consideração sua apropriação possível pela teoria política contemporânea. Existe algo de arbitrário em postularmos a divisão entre duas classes antagônicas. Por que a divisão é binária e não, digamos, ternária, com a presença de um setor médio entre elas? Ou ainda, porque Maquiavel identifica seu objeto no controle dos mecanismos do poder e não, por exemplo, no controle da distribuição da graça religiosa, fazendo da divisão um embate entre elementos seculares e religiosos?
Em segundo lugar, e mais importante, o fato da divisão civil na obra de Maquiavel não me parece ter o papel de um axioma, ou postulado conceitual, mas sim de uma conclusão empírica retirada de inúmeros exemplos históricos compilados a exaustão nas análises históricas do autor. Se isso é verdade, então o pensador da política chegaria à divisão social tanto quanto um matemático chega à conclusão de um argumento partindo de axiomas, e não simplesmente o postulando. A tese nesse sentido estaria mais para um teorema do que um axioma (para usarmos a analogia matemática corretamente). Essa interpretação ganha força uma vez que levamos a sério a tese da "similaridade de eventos" apresentada pelo autor em TL: "quem estudar a história [...] verá que os mesmos desejos e as mesmas paixões reinaram e reinam ainda em todos os governos, em todos os povos" 21 . Ou seja, dados os motores constantes da ação humana e estando essas ações contextos historicamente similares, provavelmente encontraremos os mesmos resultados. A tese da similaridade rejeita a repetição fatalista de acidentes, mas reconhece o princípio básico de uma explicação racional, i. e. uma mesma estrutura explicativa é capaz de explicar eventos empíricos distintos no tempo e no espaço.

Algo precisa se manter constante ao longo da história para que a similaridade de eventos seja possível. Quais são para Maquiavel as forças constantes das ações humanas? Mesmo reconhecendo a possibilidade de diferentes respostas para essa pergunta, para nenhuma delas a resposta é de caráter "naturalista". Isto é, que o motor das ações humanas deve ser encontrado na própria natureza dos homens ou qualquer outra diferença "ontológica" relevante, segundo a qual uns estariam naturalmente inclinados à dominação e outros, naturalmente programados à liberdade. Ao contrário: todos estaríamos sujeitos às mesmas paixões e desejos. Como afirma Maquiavel: "todos a quem faltem leis para regular sua conduta podem

21 TL I 39. 
cometer os mesmos erros [...]"²2. É importante notar também que que mesmo em suas caracterizações mais pessimistas da natureza humana, Maquiavel raramente identifica nas paixões humanas o conteúdo exato dos "humores" de classe. Em $O P$, por exemplo, o florentino nos diz que "de modo geral, pode-se dizer que os homens são ingratos, volúveis, fingidos e dissimulados, avessos ao perigo [e] ávidos de ganhos" "23. Ora, ambição (“ávidos de ganhos”) não significa necessariamente vontade de domínio, nem tão pouco segurança ("avessos ao perigo") implica necessariamente a vontade de não ser controlado. Se a existência dos humores é necessária, ela o é por motivos materiais, e não naturais, e, portanto, próprios às circunstâncias históricas, nas quais o leque de paixões humanas encontra expressão em uma forma social determinada.

Todavia, simplesmente descartar a interpretação "ontológica" não significa responder à questão a respeito da suposta necessidade da divisão social. A melhor forma de interpretarmos a natureza necessária da divisão é relacionando-a às consequências empíricas inevitáveis que se seguem à instituição de uma autoridade política. Roma e Florença seriam comparáveis não apenas porque estão situadas $n a$ historia, mas sobretudo porque vivem com historia, isto é, são sociedades históricas instituídas por uma autoridade política centralizada - ou Estado em sentido amplo - que necessariamente divide o corpo social entre comandantes e comandados. Como constata Maquiavel em TL: "[q]ualquer que seja a forma como se organize a república no máximo quarenta ou cinquenta cidadãos podem alcançar o poder" ${ }^{24}$. Instituições políticas centralizadas impõem uma série de restrições incontornáveis quanto a distribuição do poder. A principal delas é a divisão assimétrica entre, pelo menos, duas classes de pessoas opostas. Duas classes de agentes políticos estruturados por desejos contraditórios - mas não exatamente opostos - em relação ao controle dos meios da coerção.

A vantagem dessa interpretação é que ela não é estranha ao pensamento político contemporâneo. Como sintetiza o filósofo do direito H. L. A. Hart (1972, p. 165-166) a respeito da criação histórica do Estado, "os ganhos [de sua criação] são aqueles de adaptabilidade às mudanças, certeza e eficiência, e eles são imensos; o custo [...] é o risco de que o poder centralizado possa ser usado para a opressão"25. A aplicação difusa da coerção em comunidades sem Estado possui certos inconvenientes em relação à organização centralizada da ação coletiva por meio de regras generalizáveis. Entre os principais inconvenientes estariam a incerteza quanto a interpretação e aplicação de regras, a instabilidade de manter acordos ao longo do tempo e a ausência de agentes especializados na interpretação e aplicação das regras sociais. A instituição de uma autoridade política é normalmente justificada como a melhor forma de solucioná-las. Entendida como a centralização de normas de conduta cuja obediência é regularmente sustentada pela coerção, autoridades políticas solucionariam de modo eficiente cada um dos inconvenientes da anarquia institucional. Assumamos que a criação de autoridades políticas seja de fato justificada (algo que, por exemplo, um anarquista não aceitaria). Uma de suas consequências necessárias é justamente a criação de novas formas possíveis de dominação. No caso de Maquiavel muito provavelmente a existência de autoridades políticas centralizadas (ainda que diferentes do Estado moderno) era a única realidade política conhecida. A ausência de poder centralizado implicava a própria ausência do poder, ou, em seus termos, a “desordem".

22 TL I 58.

23 OP XVII.

24 TL I XVI.

25 Segundo a famosa teoria de Hart acerca do direito (entendido como a centralização de normas de conduta cuja obediência é sustentada pela coerção), sistemas jurídicos nasceriam da união entre regras de conduta primárias, que regulam nossas interações pessoais em qualquer contexto humano conhecido, e regras secundárias que, por meio de instituições jurídicas, servem para organizar essas mesmas regras primárias. Ver a esse respeito Hart (1972, cap. V). 
Os argumentos de justificação racional dos Estados, fundadas muitas vezes no "estado natural" do homem, ainda estavam por vir.

Mais recentemente, a antropologia política verificou empiricamente a existência de formas harmônicas de vida política sem Estado. Como afirma o antropólogo Pierre Clastres: "a desigualdade ignorada pelas sociedades primitivas é aquela que divide os homens em detentores do poder e subjugados ao poder", isto é, "a que divide o corpo social em dominantes e dominados" (CLASTRES, 1982, p. 113). Hoje reconhecemos que sociedades sem Estado podem constituir formas de vida social na qual a não existência de autoridades centralizadas não é entendida como uma falta. Mas isso tudo não retira a validade do argumento de Maquiavel: a instituição da autoridade política cria duas posições estruturais no corpo social: os detentores dos meios do controle social (grandes) e aqueles que encontram-se sujeitos a esse controle (povo).

É possível encontrarmos corroboração da interpretação segundo a qual é a própria instituição da autoridade política quem estabelece a divisão social no argumento de Maquiavel. Em primeiro lugar, nunca encontraremos um critério material de identidade para as classes sociais. "Povo" é aquele que reivindica a não dominação - viver como quiser para além do controle social. Contudo, aqueles que reivindicam esse ideal são, justamente, aqueles que se encontram na posição de comandados, $i$. e os que não detêm os mecanismos do poder. Povo não identifica uma classe de pessoas específicas mas sim uma posição social vazia a ser preenchida por critérios legais historicamente diferentes ("nãoaristocratas", "não-oligarcas", "não-burocratas", etc.) uma vez que os modos do exercício do poder (e não sua natureza) variam no tempo e no espaço ${ }^{26}$.

Em segundo lugar, ela também é compatível com a tese da similaridade de eventos. Uma vez instituída a divisão, os agentes políticos encontram diante de si uma estrutura de relações capaz de dar forma ao leque de paixões existentes em potencialidade em qualquer pessoa. Desejo de ganho se torna vontade de comandar, segurança se torna vontade de evitar o controle opressivo da conduta, etc. Podemos explicar assim como a instituição de uma autoridade política afeta a "alquimia" das paixões humanas sem recorrermos à sua naturalização.

Finalmente, voltemos à distinção sugerida anteriormente entre comando e opressão. Se por um lado a luta popular pela não-opressão é necessária para a liberdade da república, o desejo de não haver comando algum - não ser comando por ninguém não seria uma reivindicação exequível já que, em última instância, significara a dissolução da própria autoridade política. De fato, quando analisamos as pretensões revolucionárias dos Ciompi em $H F$, é exatamente essa conclusão que encontramos. Segundo Maquiavel, ao dirigir-se ao povo em armas, o líder revolucionário Ciompi os teria exortado a levar às últimas consequências suas reivindicações de liberdade: "quantas vezes ouvi vossas queixas da ganância de vossos superiores e da injustiça de vossos magistrados! Está na hora de não só vos libertardes deles, como também de vos tornardes tão superiores a eles que eles tenham mais queixas e temores de nós do que vós deles"27.

Se essas palavras inflamaram os ânimos da república "para o mal”, como sustenta Maquiavel, isso se deu na medida em que elas instigaram o povo a ser tão superior quanto os grandes. Eles não apenas combateram os excessos dos grandes, lutando contra sua opressão, mas além disso questionaram o próprio fato de serem comandados. Reivindicaram a abolição da posição de comando. É preciso admitir que onde Estado, onde os meios da coerção forem separados do corpo social, necessariamente existirá uma estrutura de poder assimétrica entre os agentes políticos. É nesse sentido que, para Maquiavel, abolir a posição dos dominados é pretender abolir a própria

${ }^{26}$ Cf. TL I LV.

27 HF III 13 (ênfase acrescida). 
ação política. Existiria algo de autocontraditório e, portanto, perigoso, nessa tentativa, tanto quanto confiar apenas na boa vontade dos homens em assuntos políticos. O mito da harmonia social seria tão perigoso quanto o da igualdade de poder.

Essa, me parece, é a principal lição política extraída da tese da divisão civil.

\section{II}

Deve o povo necessariamente permanecer em sua posição? Deve ele se satisfazer na pobreza do poder? Acredito que a teoria política que se entende como herdeira dessa tese tenha duas respostas diferentes a essas perguntas. A primeira dessas vertentes procura oferecer uma solução popular ou "plebeísta" para o equilibro das repúblicas, a segunda, procura reinterpretá-la a partir de ideais democráticos formulados posteriormente a Maquiavel. A primeira delas toma a posição de fala do povo na terceira pessoa - o povo são eles - a outra, na segunda pessoa - nós somos o povo. Em última instância temos duas formas distintas de entendermos o ideal de soberania popular: uma neorepublicana e outra democrática.

Uma objeção preliminar poderia ser levantada contra essa classificação. Segundo essa objeção, a literatura recente referente à teoria dos humores tende, de fato, a dividir o pensamento republicano em dois grandes grupos. De um lado, existiria um grupo de teorias para as quais a divisão é entendida como uma relação de oposição e equilíbrio, do outro, as que a interpretam como uma relação de conflito de forças assimétricas (ver, por exemplo, ADVERSE, 2007, p. 41-42). Como viemos, a tese permite diferentes abordagens dependendo de como a forma e conteúdo dos humores é definido.
Todavia, acredito que, do ponto de vista da pergunta que estamos colocando à tese da divisão essa não parece ser a diferença mais importante, uma vez que ambos os grupos partilham o mais fundamental, a saber: a posição normativa do papel do legislador, isto é, quanto a natureza do agente político para quem a tese é enunciada.

Tomemos a interpretação do historiador Quentin Skinner como um exemplo paradigmático da visão oposição e equilíbrio. Segundo Skinner, "motivadas inteiramente por seus interesses egoístas, as facções [grandes e povo] serão assim guiadas - como que por uma mão invisível - rumo a promoção do interesse público" (SKINNER, 1981, p. 106) ${ }^{28}$. Em outra passagem o autor reafirma essa mesma interpretação ao concluir que, para Maquiavel, "a única maneira de prevenir que isso ocorra [que os grandes dominem o povo] é organizando a comunidade política de tal forma que cada e todo cidadão seja igualmente capaz de tomar parte na determinação da ação do corpo político como um todo" (SKINNER 1984, pp. 213214). A divisão é entendida como uma oposição de forças sociais e caberia ao legislador organizá-las de modo a produzirem o bem comum. Particularmente, caberia ao legislador republicano buscar os mecanismos institucionais mais adequados à tradução do conflito vicioso em disputa virtuosa. Acredito que, nesse sentido, Skinner concordaria com a famosa tese de James Madison, célebre leitor de Maquiavel, quando, em $O$ Federalista $n$. 10 ele identifica o bom regime político como sendo o resultado de um arranjo institucional estável entre forças sociais conflitantes (HAMILTON; MADISON; JAY, 2003 [1788] cap. 10). Nesse tipo de análise, ambos os humores são igualmente nocivos à sociedade cabendo ao legislador colocá-las em equilíbrio.

\footnotetext{
${ }^{28}$ Na passage original: "Although motivied intirely by their selfish interests, the factions will thus be guided, as if by an invisible hand, to promote the public interest in all their legislative acts: 'all the laws made in favour of liberty' will 'result from their disacord". É preciso enfatizar que isso não significa que o próprio neorrepublicanismo de Skinner conceba a política por meio da analogia da mão invisível - algo que o historiador rejeita explicitamente (cf. SKINNER 1990, pp. 304-305). O ponto é apenas que a visão da oposição e equlíbrio tende a conceber a divisão social a partir de uma perspectiva objetiva, como um outro a ser bem governado, e não como um nós que precisa se auto-governar. Agredeço aos comentários de um parecerista anônimo por me ajudar a esclarecer esse ponto.
} 
Não existe essa equivalência normativa entre os humores nas formulações do conflito assimétrico. No "populismo feroz" proposto recentemente por John Mccormick, por exemplo, cabe ao legislador fornecer meios para que as reivindicações populares irrompam na sociedade contra o status quo político. Isso porque, em última instância, a ordem social favoreceria naturalmente às elites do poder. Seria equivocado falarmos propriamente em "equilíbrio" nessa caso uma vez que, segundo Mccormick, o modelo maquiaveliano estaria fundado em "um arranjo pacífico, bucólico ou tranquilo das interações sociais" (Mccormick 2001, p. 302), mas sim no conflito permanente entre uma vontade popular em favor da liberdade política e uma força coercitiva motivada por interesses pessoais. É verdade que tanto o tom da interpretação, como a radicalidade das consequências nas duas leituras da tese são diferentes. Contudo, como afirmei, acredito que em ambos os casos - seja no equilíbrio opositivo ou no conflito assimétrico de forças -o regime político aceita a legitimidade da própria divisão. Bem assimilada à ordem social (Skinner) ou permanentemente conflituosa (Mccormick), ambas as formas de neorepublicanismo concebem o povo como uma força social exterior à própria legitimidade política na medida em que eles - o povo, sujeito moral distinto do legislador - podem ser usados de maneira virtuosa pelo legislador. Ao colocar-se fora da sociedade, isto é, ao se colocarem fora da divisão entre grandes e povo, ambas as teorias tratam o sujeito do conhecimento político como um sujeito que não partilha a posição de povo. Na verdade, o legislador-leitor, aquele para quem a tese é enunciada, não pode ser posicionado nem com o povo nem entre os grandes, uma vez que cabe ao agente usar ambas as forças objetivas da organização política para o bem geral. Fundadas nessa exclusão, ambas as teorias acabam transformando a posição estrutural do povo direta (como no caso de Skinner) ou indiretamente (como no caso de Mccormick) em um objeto necessário à boa ordenação social.
No limite, portanto, a desigualdade de forças entre as classes sociais é uma das condições necessárias para a eficiência institucional do bom regime, e a escassez estrutural de poder popular é um recurso social útil do ponto de vista das consequências institucionais. Mesmo no caso do populismo de Miccormick não há identificação alguma entre o sujeito do conhecimento político (aqueles e aquelas que leem os livros de Mccormick) e a posição objetiva do povo. Ambas as interpretações repactuam os termos da organização social tomando os humores populares como algo a ser manejado de modo consequente - ao estilo de James Madison.

A segunda forma de reapropriação da tese da divisão social parece mais frutífera de uma perspectiva democrática. Ainda que, para que seja de fato democrática precisaríamos ir além, em termos históricos e conceituais, da tese original de Maquiavel. Isto é, para que a divisão seja compatível com o que estamos entendendo por posição democrática, é preciso conceber o papel do povo em uma chave normativa diferente. Do ponto de vista de uma constituição democrática, todos e todas devemos ser o povo. De acordo com a justificação democrática da legitimidade do poder, não existe a possibilidade de um lugar de fala para sujeitos fora dos limites da igual cidadania. Isso não significa, é claro, que não existirão desigualdades sociais ou que todas e todos terão à disposição sempre os mesmos recursos materiais, como o acesso privilegiado aos meios da coerção social. Novas aristocracias de fato (mas não de direito) surgem constantemente em uma sociedade democrática. $\mathrm{O}$ ponto a ser ressaltado é que mesmo para o sentido factual de dominadores, aqueles que possuem mais poder precisam justificar seus interesses e sua própria posição social na forma da reivindicação popular: "nós o povo". De um ponto de visto normativo, todos somos iguais em nossa autoridade de reivindicar a autoridade democrática. Existe uma igualdade de jure de poder. Nenhuma divisão social pode ser válida se não atender a esse critério formal mínimo. 
Se o que apresentei ate aqui estiver correto, então nesse caso, o legislador, aquele que reivindica o melhor uso da coerção política ou demanda a mudança das regras sociais que nos organizam enquanto comunidade política, não se encontra fora da divisão social. Muito pelo contrário, só há um legislador possível para o pensamento democrático e ele se encontra na posição estrutural do povo.

Podemos compreender melhor esse movimento tortuoso ao lembramos que, a rigor, a tese da divisão depende da existência de uma terceira perspectiva. Isso fica claro quando Maquiavel (2010, p. 46) apresenta sua tese a um interlocutor determinado, no caso, o príncipe ao qual sua obra é dedicada:

[t]ampouco pretendo que se considere presunção o fato de que um homem de baixo e ínfimo estado [Maquiavel] ouse discorrer e ditar regras sobre o governo dos príncipes; isto porque, assim como os desenhistas de paisagem se põem num nível abaixo a fim de discernir a natureza dos montes e lugares altos, e no topo dos montes para observar as zonas baixas, do mesmo modo, para bem conhecer a natureza dos povos, é preciso ser príncipe, e, para conhecer bem a dos príncipes, é necessário pertencer ao povo ${ }^{29}$.

Para além da divisão entre grandes e povo é preciso assumir que aquele que conhece as forças sociais, aquele que ousa "ditar regras", é diferente do objeto ao qual as regras se aplicam. Se somos sujeitos do conhecimento ao estudar o poder não podemos deixar ser agentes sociais concretos (grandes ou povo) em nossas vidas cotidianas. Evidentemente o bom legislador, no caso o príncipe, precisa conhecer bem as duas perspectivas para, com isso, poder calcular os efeitos que suas decisões legislativas terão sobre as forças sociais. Mas é justamente por isso que o legislador maquiaveliano é conceitualmente definido como uma terceira perspectiva, constitutindo assim a visão daquele que compreende as forças sociais na terceira pessoa - "eles" o povo, "eles" os grandes.
Essa me parece ser a última consequência da objetividade do conhecimento político e, infelizmente, pouco discutida entre os especialistas de Maquiave ${ }^{30}$. ao concebermos as relações de poder como forças impessoais, ao aceitarmos, por exemplo, a tese da similaridade dos eventos, quase que imediatamente somos expulsos da condição de objeto do conhecimento político para nos tornarmos sujeitos desse conhecimento. "Nós", sujeitos do conhecimento, somos também povo ou grande e é de se esperar que essa nova perspectiva traga consequências práticas importantes para a nossa ação no mundo social. É claro que para Maquiavel o conjunto possível de sujeitos era extremamente reduzido. Um príncipe novo, amigos humanistas, um tirano estrangeiro, etc. Talvez essa escassez explique o ceticismo do autor quanto a possibilidade de uma república de cidadãos ativos em seu próprio tempo histórico. Mas e se todos tomarmos consciência da tese da divisão?

É em vista dessa terceira perspectiva do argumento que devemos interpretar a bela afirmação de Claude Lefort segundo a qual, em Maquiavel, "o movimento do saber implica o movimento de libertação da ação"(LEFORT, 1972, V 3, p. 529) ${ }^{31}$. Não é à toa que uma obra superficialmente contrária à liberdade do povo como $O$ Príncipe foi lida na tradição política esclarecida como manual contra a tirania. Compreender o poder como uma luta entre forças sociais objetivas é permitir que, ao conhecermos a sociedade, possamos também alterá-la.

Ao reconhecer que a divisão social é causada pela própria instituição de uma autoridade política, por mais justa e benevolente que almeje ser, o vocabulário de Maquiavel pode retornar como um pesadelo contra toda forma de pensamento igualitário ingênuo em relação ao poder. As posições de comando e comandados não podem ser suprimidas, ao contrário, constituem a divisão necessária para justificar o poder político."Melhor do que Marx",

\footnotetext{
29 OP Dedicatória.

${ }^{30}$ Uma exceção é a obra de Claude Lefort. Ver, Lefort (1972).

${ }^{31}$ Utilizei-me nesse trecho da tradução proposta por José Luiz Ames (manuscrito).
} 
afirma Lefort, Maquiavel teria esclarecido "a função do poder do Estado no processo da formação da sociedade civil" (LEFORT, 1979b, p. 154) ${ }^{32}$. Basta o poder ser um recurso escasso para que exista a posição do povo como lugar da desigualdade. Eis o lado duro da lição maquiaveliana.

Devemos, contudo, nos satisfazer na pobreza das possibilidades democráticas?

Não necessariamente. A proposta de Claude Lefort de conceber a democracia como um regime no qual o poder encontra-se permanentemente indeterminado, seria uma boa interpretação democrática de Maquiavel (LEFORT, 1981). Em primeiro, Maquiavel nos ensina que a opressão de classe não é necessária, ao contrário, é até mesmo indesejável para a manutenção de boas leis. Ser comandado não significa a mesma coisa que ser oprimido. Se isso é verdade, então, talvez, exista uma forma de exercício do poder político que não oprima necessariamente. Se por um lado a divisão é inevitável, por outro, como vimos, ela é também vazia. Não se trata de uma categoria material a qual os indivíduos encontram-se atados como que por necessidade. A variedade de conteúdos históricos com os quais diferentes sociedades a preenchem não nos deixa dúvidas. $\mathrm{Na}$ verdade, podemos afirmar que basta tomarmos consciência da divisão social como uma relação formal, e não como uma desigualdade de ordem natural entre os homens, para sermos imediatamente impelidos a alterara. A teoria democrática poderá estruturar os meios de coerção de tal modo que todos possam ocupá-lo, ou ainda, de maneira mais correta, que ninguém possa se apropriar do governo de maneira permanente.

Essa é a forma democrática de se apropriar a tese da divisão social. Contrária, portanto, à visão da oposição e equilíbrio tal como apresenta por alguns autores neorepublicanos. É verdade que não podemos construir uma moralidade política inteiramente democrática apenas com Maquiavel. Outras fontes são necessárias. O que falta? Posso apenas sugerir uma linha de investigação. Acredito que o principal componente ausente é o pressuposto normativo central de qualquer teoria política contemporânea, mas não necessariamente da teoria política do Renascimento, o ideal segundo o qual cada indivíduo é irredutivelmente valioso do ponto de vista moral e que, portanto, todos devemos ser tratados com igual consideração e respeito pelas instituições políticas. É essa concepção de igualdade que encontramos, por exemplo, nos principais filósofos da legitimidade democrática: Rousseau e Kant. O primeiro é especialmente importante. Logo na introdução de seu Discurso Sobre a Origem da Desigualdade, Rousseau (1989) estabelece sua famosa distinção conceitual entre duas formas distintas de desigualdade, naturais e morais (ou, diríamos, sociais) ${ }^{33}$. Apenas desigualdades sociais são dignas de avaliação moral, na medida em que são fundadas em práticas humanas reproduzidas por nossas ações e, portanto, capazes de serem responsabilizadas entre sujeitos livres e iguais. Mesmo que as desigualdades naturais sejam arbitrárias de um ponto de vista moral, para a tradição democrática iniciada com Rousseau, somos perfeitamente responsabilizáveis pelas consequências que essas desigualdades engendram em arranjos sociais criados por convenções, isto é, por meio da ação humana livre ${ }^{34}$. Mesmo que estruturas políticas centralizadas estabeleçam ou potencializem desigualdades entre homens e mulheres, somos moralmente responsáveis por justificá-las entre iguais. Não existe no pensamento democrático uma perspectiva normative exterior à perspectiva do povo. Toda forma de governo é auto-governo, pelo menos no que diz respeito aos princípios que justificam o exercício da autoridade política sobre agentes morais livres e iguais. O projeto de encontrar uma fundamentação racional

32 Ênfase acrescida.

${ }^{33}$ É importante ressaltar que Rousseau define a desigualdade de poder política ("a diferença de privilégio [...] em se fazer obedecer") como um caso de desigualdade social, e não natural, entre agentes morais (ROUSSEAU, 1989, Introdução).

${ }^{34}$ Ver, a esse respeito, a esclarecedora reconstrução do argumento de Rousseau feita por Frederik Neuhouser (2014, p. 16-17). 
do poder entre iguais, desenvolvido pela tradição democrática desde então, é justamente a resposta ao desafio lançado por Machiavel.

\section{Referências}

ADVERSE, H. Maquiavel, a república e o desejo de liberdade. Trans/Form/Ação, Marília, v. 30, n. 2, p. 33-52, 2007.

BERLIN, I.The originality of Machiavelli. In: HARDY, H.; HAUSHEER, R. The proper study of mankind: an anthology of essays. New York: Farrar, Strauss and Giroux, 1977. p. 269-325.

BIGNOTTO, N. Matrizes do republicanismo. Belo Horizonte: UFMG, 2013.

CLASTRES, P. Liberdade, mau encontro, inominável. In: SANTOS, L. G. (Org.). Discurso da servidão voluntária. São Paulo: Brasiliense, 1982. p. 109-123.

HART, H. L. A. The concept of law. Oxford: Claredon Press, 1972.

HAMILTON, A.; MADISON, J.; JAY, J. The federalist: with letters of Brutus. Cambridge: Cambridge Press, 2003.

LEFORT, C. A invenção democrática: os limites do totalitarismo. São Paulo: Brasliense, 1981.

. Le travail de l'oeuvre Machiavel. Paris: Gallimard, 1972.

Maquiavel: a dimensão econômica do político. In: . As formas da história: ensaios de antropologia política. São Paulo: Brasiliense, 1979b. p. 141-154.

. ONascimento da ideologia e do humanismo. In: . As formas da história: ensaios de antropologia política. São Paulo: Brasiliense, 1979a. p. 251-294.

MAQUIAVEL, N. História de Florença [HF]. São Paulo: M. Fontes, 2007.

. Maquiavel: comentários sobre a primeira década de Tito Lívio [TL]. Brasília: UNB, 1979.

. O Príncipe [OP]. São Paulo: Penguin \& Companhia, 2010.

MCCORMICK, J. P. Machiavellian democracy: controlling elites with ferocious populism. American Political Science Review, Baltimore, v. 95, n. 2, p. 297-313, 2001.

NEUHOUSER, F. Rousseau's Critique of Economic Inequality. Philosophy \& Public Affairs, v. 41, n. 3, p. 193-225, 2013.

PETTIT, P. Republicanism: a theory of freedom and government. Oxford: Oxford Press, 1997.

ROUSSEAU, J. J. Discours sur l'origine et les foundaments de l'enigalite parmi les hommes. Paris: Gallimard, 1989.

SKINNER, Q. As fundações do pensamento político moderno. São Paulo: Companhia das Letras, 2009.

- Liberty before liberalism. Cambridge: Cambridge Press, 1997.

. The republican ideal of political liberty. In: BOCK, G., SKINNER, Q.; VIROLI, M. (Ed.). Machiavelli and Republicanism. Cambridge: Cambridge Press, 1990. pp. 293-308.

The idea of negative liberty: philosophical and historical perspectives. In: ROTY, R., SCHNEEWIND, J. B.; SKINNER, Q. (Ed.). Philosophy in history: essays on the historiography of philosophy. Cambridge: Cambridge Press, 1984, pp. 193-224.

. Machiavelli. Toronto: Sterling Publisher, 1981.

WINTER, L. M. A teoria dos humores de Maquiavel: a relação entre conflito e liberdade. Cadernos de Ética e Filosofia Politica, São Paulo, v. 2, n. 19, p. 43-75, 2011.

Recebido em: 25 abr. 2015 Aceito em: 19 maio 2016. 
